Article

\title{
A Modified Sequential Deposition Route for High-Performance Carbon-Based Perovskite Solar Cells under Atmosphere Condition
}

\author{
Jinyu Wu ${ }^{1}$, Lei Zhang ${ }^{1,2}$, Qiao Kang ${ }^{1}$, Hongxi Shi ${ }^{1}$, Long $\mathrm{Li}^{2}{ }^{2}$, Dan Chi ${ }^{1, *} \mathbb{C}$, Shihua Huang ${ }^{1, *}$ and Gang He ${ }^{2} \mathbb{D}$ \\ 1 Provincial Key Laboratory of Solid State Optoelectronic Devices, Zhejiang Normal University, \\ Jinhua 321004, China; wjyzjnu@zjnu.cn (J.W.); zhanglei2017@cug.edu.cn (L.Z.); kangqiao@zjnu.edu.cn (Q.K.); \\ SHongxi@zjnu.edu.cn (H.S.) \\ 2 Faculty of Materials Science and Chemistry, China University of Geosciences, Wuhan 430074, China; \\ lilong@cug.edu.cn (L.L.); gh6321@cug.edu.cn (G.H.) \\ * Correspondence: chidan@zjnu.edu.cn (D.C.); huangshihua@zjnu.cn (S.H.)
}

Citation: Wu, J.; Zhang, L.; Kang, Q.; Shi, H.; Li, L.; Chi, D.; Huang, S.; He, G. A Modified Sequential Deposition Route for High-Performance CarbonBased Perovskite Solar Cells under Atmosphere Condition. Molecules 2022, 27, 481. https://doi.org/ $10.3390 /$ molecules 27020481

Academic Editor: Zaizhu Lou

Received: 16 December 2021

Accepted: 6 January 2022

Published: 13 January 2022

Publisher's Note: MDPI stays neutral with regard to jurisdictional claims in published maps and institutional affiliations.

Copyright: (C) 2022 by the authors. Licensee MDPI, Basel, Switzerland. This article is an open access article distributed under the terms and conditions of the Creative Commons Attribution (CC BY) license (https:/ / creativecommons.org/licenses/by/ $4.0 /)$.

\begin{abstract}
Carbon-based hole transport material (HTM)-free perovskite solar cells have exhibited a promising commercialization prospect, attributed to their outstanding stability and low manufacturing cost. However, the serious charge recombination at the interface of the carbon counter electrode and titanium dioxide $\left(\mathrm{TiO}_{2}\right)$ suppresses the improvement in the carbon-based perovskite solar cells' performance. Here, we propose a modified sequential deposition process in air, which introduces a mixed solvent to improve the morphology of lead iodide $\left(\mathrm{PbI}_{2}\right)$ film. Combined with ethanol treatment, the preferred crystallization orientation of the $\mathrm{PbI}_{2}$ film is generated. This new deposition strategy can prepare a thick and compact methylammonium lead halide $\left(\mathrm{MAPbI}_{3}\right)$ film under high-humidity conditions, which acts as a natural active layer that separates the carbon counter electrode and $\mathrm{TiO}_{2}$. Meanwhile, the modified sequential deposition method provides a simple way to facilitate the conversion of the ultrathick $\mathrm{PbI}_{2}$ capping layer to $\mathrm{MAPbI}_{3}$, as the light absorption layer. By adjusting the thickness of the $\mathrm{MAPbI}_{3}$ capping layer, we achieved a power conversation efficiency (PCE) of $12.5 \%$ for the carbon-based perovskite solar cells.
\end{abstract}

Keywords: perovskite solar cell; hole transport material-free; capping layer; crystallization orientation

\section{Introduction}

Lead halide perovskites have excellent optoelectronic properties, such as a high absorption coefficient, high carrier mobility, and long carrier recombination life. Due to these excellent properties, the PCE of perovskite solar cells (PSCs) achieved an explosive development from $3.8 \%$ to $25.7 \%$ in a few years [1-6]. Despite the advance in the PCE of PSCs, the moisture instability of the perovskite layer, under ambient conditions, is one of the most urgent problems to be resolved.

As known to us all, the moisture instability of the perovskite layer reduces the lifetime of the solar cells and, thus, limits their application outdoors. Under the combined action of humidity, oxygen, and ultraviolet light, the perovskite active layer will rapidly decompose [7-10]. Moreover, the majority of PSCs use hole transport material (HTM) to facilitate hole extraction. ( $\mathrm{N}, \mathrm{N}$-di-methoxy-phenyl amine)-9,9-spirobifluorene (spiroOMeTAD) is a common hole transport material in perovskite solar cells, usually doped with bis(trifluoromethane)sulfonimide lithium salt to improve its conductivity. However, lithium salts easily absorb moisture and cause device degradation [11]. The application of HTM also enhances the complexity of device fabrication. Hence, HTM-free PSCs should be investigated. In 2013, Han proposed a full printable HTM-free perovskite solar cell with a carbon electrode [12]. Due to the unique ambipolar property of perovskite, HTMfree perovskite solar cells can obtain a high PCE of 14.3\% [13]. Since the hydrophobic 
carbon electrode can block moisture, the stability of the perovskite solar cell in a humid environment is substantially improved. For the traditional perovskite solar cells, a metal electrode and HTM are needed. However, the metal electrodes are usually deposited by a thermal evaporation process, under high-vacuum conditions, which is a high-cost process. In comparison to metal electrodes, carbon electrodes avoid the phenomenon whereby metal diffuses into the perovskite layer and leads to device degradation. Additionally, carbon electrodes are beneficial to extract holes, eliminating the need to use expensive and unstable HTM, which promotes the commercialized production of low-cost and stable HTM-free perovskite solar cells. As a result, we fabricated the HTM-free perovskite solar cell based on a carbon electrode.

As the hybrid organic-inorganic halide perovskite is sensitive to moisture and oxygen, most of the preparation processes are completed in a glove box $[6,14]$. Fabricating highefficiency and stable perovskite solar cells under atmospheric conditions for commercial application is still a huge challenge [15]. It is difficult to prepare a uniform and dense perovskite film under high humidity. Low-quality perovskite films have many holes. Through these holes, the carbon electrode contacts the electron transport layer directly, resulting in carrier recombination and a reduced carrier concentration. Therefore, the gap between quasi-Fermi levels is decreased, which determines the value of the open-circuit voltage (VOC) [16]. In order to reduce carrier recombination, insulating layers were introduced. Cheng used a mesoporous $\mathrm{SiO}_{2}$ insulating layer to prepare HTM-free perovskite solar cells in a $50 \%$ humidity environment, and achieved an efficiency of $11 \%$ [17]. Han et al. proposed a drop-cast method with a mesoporous $\mathrm{ZrO}_{2}$ insulating layer to prepare perovskite solar cells with a PCE of $13 \%$ under atmospheric conditions [18]. The high-temperature sinter process of the insulating layer increases the cost and energy consumption considerably. The morphology of the perovskite film tremendously depends on the morphology of the $\mathrm{PbI}_{2}$ film, so it is key to acquire a uniform and dense $\mathrm{PbI}_{2}$ film. Compared to the one-step method, the sequential deposition method has the advantages of controllable perovskite grain size and reproducibility. However, there is the problem that $\mathrm{PbI}_{2}$ cannot be completely converted to $\mathrm{MAPbI}_{3}$ in a short period of time; for example, converting $200 \mathrm{~nm}$ thick $\mathrm{PbI}_{2}$ to perovskite completely takes $2 \mathrm{~h}$ or longer, while the perovskite will dissolve into the solution in the same amount of time [19]. Hence, exploring new processes for fabricating high-quality and thick perovskite film with no $\mathrm{PbI}_{2}$ residue, under atmospheric conditions, is greatly needed.

Here, we propose a modified sequential deposition process to achieve this goal; $N, N$ dimethylformamide (DMF) and dimethyl sulfoxide (DMSO) mixture solvent was applied to improve the morphology of the $\mathrm{PbI}_{2}$ film. The mixed solvent inhibited the heterogeneous nucleation process of $\mathrm{PbI}_{2}$ during the spin-coating process under atmospheric conditions and high humidity, due to the intermediate phase of $\mathrm{PbI}_{2}(\mathrm{DMSO})_{\mathrm{x}}$, resulting in the formation of uniform and dense $\mathrm{PbI}_{2}$ wet films. Subsequently, ethanol solvent treatment was introduced to obtain $\mathrm{PbI}_{2}$ films with a unique flaky morphology and a reduced (001) preferred orientation, which could promote the complete conversion of $\mathrm{PbI}_{2}$ to perovskite. We obtained perovskite films with different thicknesses by adjusting the thickness of $\mathrm{PbI}_{2}$. The experimental results show that the thick active layer can act as a natural insulating layer to block the contact between $\mathrm{TiO}_{2}$ and carbon effectively, and decrease the carrier recombination probability. When the thickness of $\mathrm{PbI}_{2}$ is $800 \mathrm{~nm}$, the highest open-circuit voltage $(968 \mathrm{mV})$ and highest efficiency (12.5\%) were achieved. More importantly, this modified sequential deposition method exhibited good repeatability for the preparation of perovskite film under atmospheric conditions.

\section{Results and Discussion}

The HTM-free perovskite solar cells in this study were structured as fluorine-doped tin oxide (FTO)/ compact $\mathrm{TiO}_{2} /$ mesoporous $\mathrm{TiO}_{2} / \mathrm{MAPbI}_{3}$ capping layer/carbon, as illustrated in Figure 1a. The $\mathrm{MAPbI}_{3}$ layers were formed by the sequential deposition method, and the carbon electrodes were prepared using the doctor-blade method with a commercial 
carbon paste. The band structure alignment of the cell is shown in Figure 1b. We found that the energy levels of these materials match well and the photo-generated carriers can be extracted by the electrodes. Compared with the traditional sequential deposition method, as displayed in Figure 1c, the modified sequential deposition method added DMSO to the $\mathrm{PbI}_{2}$ solution, with a 9:1 ratio of DMSO:DMF, and developed the surface engineering by treating the $\mathrm{PbI}_{2}$ wet films with ethanol, as illustrated in Figure 1d.

(a)

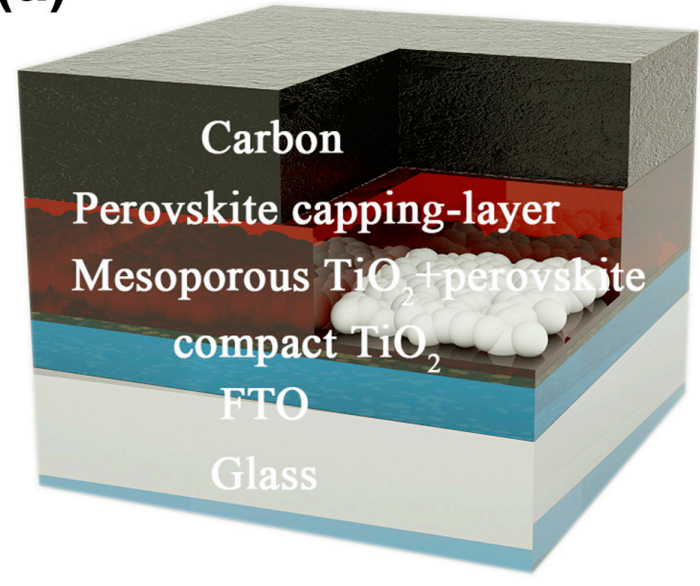

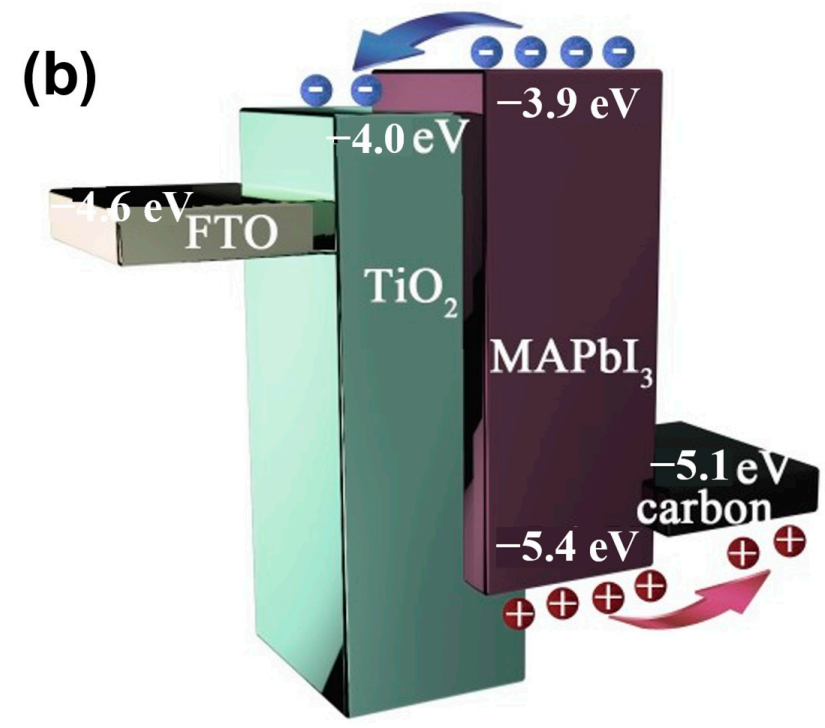

(c)

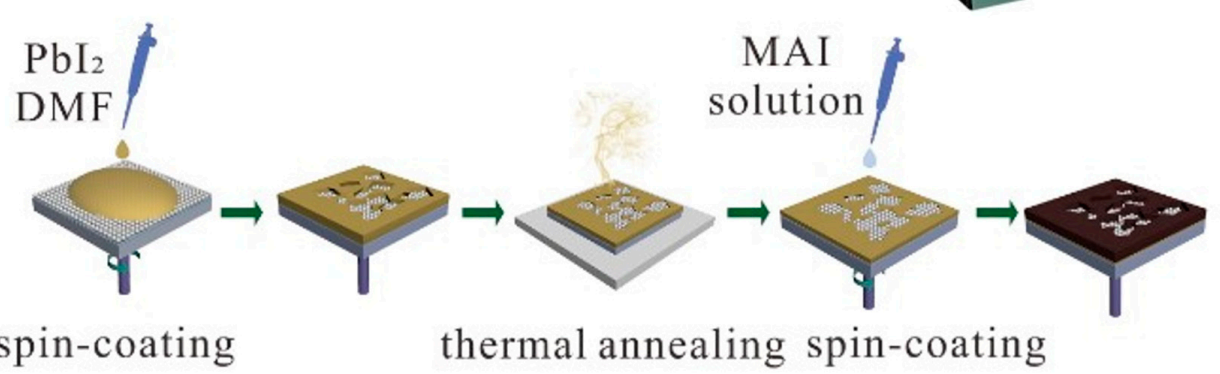

(d)

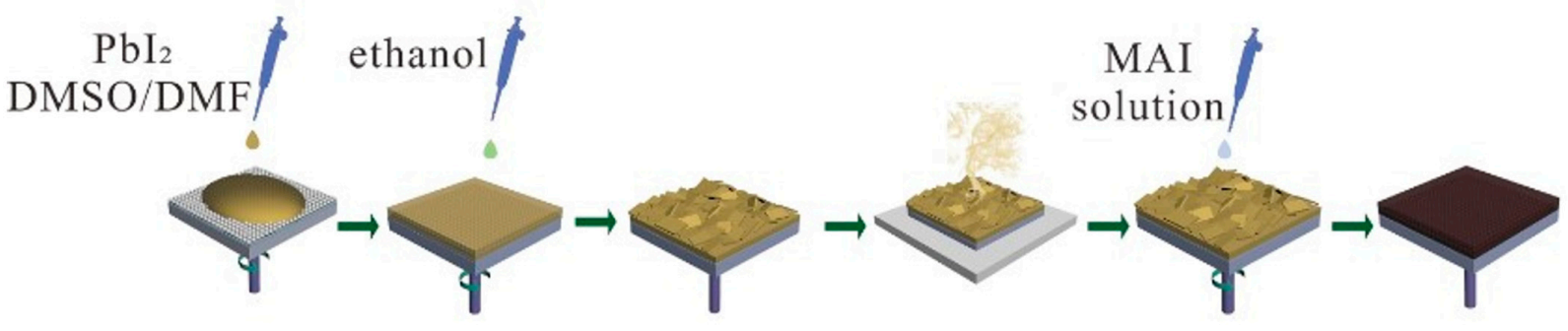

spin-coating spin-coating

Figure 1. Schematic demonstrating the (a) device architecture, (b) energy level alignment, (c) manufacture process of perovskite thin films by primal and (d) modified sequential deposition methods.

In the sequential deposition process, the quality of the perovskite film was decided by the $\mathrm{PbI}_{2}$ film [20]. Cheng et al. found that when the humidity is higher than $20 \% \mathrm{RH}$, $\mathrm{PbI}_{2}$ tends to exhibit an isolated structure, due to the moisture-induced heterogeneous nucleation and crystallization of $\mathrm{PbI}_{2}$ [21]. Our results indicate that the $\mathrm{PbI}_{2}$ thin films spin-coated under atmospheric conditions and in high humidity are coarse when using the $\mathrm{PbI}_{2}$ solution in $\mathrm{DMF}$, whereas the $\mathrm{PbI}_{2}$ thin films are smooth when using the $\mathrm{PbI}_{2}$ solution in the DMF and DMSO mixture solvent under the same conditions, as shown in Supplementary Materials Figure S1. In Figure 2a, we can observe that the coarse $\mathrm{PbI}_{2}$ thin 
film exhibits an isolated branching structure, resulting in poor coverage of the $\mathrm{MAPbI}_{3}$ thin film. This can be demonstrated by the scanning electron microscopy (SEM) image of $\mathrm{MAPbI}_{3}$ in Figure 2c. On the contrary, the smooth $\mathrm{PbI}_{2}$ film exhibits the ideal morphology, with a high coverage rate and small pin-holes, as shown in Figure $2 b$. Therefore, the resulting $\mathrm{MAPbI}_{3}$ thin film exhibits a dense-grained uniform morphology, as presented in Figure 2d. Figure 2e shows the XRD patterns of the $\mathrm{PbI}_{2}$ films both without and with annealing, which explains the retarded crystallization of $\mathrm{PbI}_{2}$ with DMSO during the spincoating process. Because there are so many diffraction peaks in the XRD figure, and most of them are the same for all the four $\mathrm{PbI}_{2}$ films, we use different symbols to distinguish these diffraction peaks from different materials. Without being annealed, the DMF-based $\mathrm{PbI}_{2}$ wet film shows an obvious diffraction peak centered at $12.6^{\circ}$, indexing to the (001) crystal plane of $\mathrm{PbI}_{2}$. These data imply that parts of $\mathrm{PbI}_{2}$ have crystallized in the spin-coating process. However, this diffraction peak was not observed in the $\mathrm{PbI}_{2}$ wet film with DMSO, indicating its amorphous feature. After heating the $\mathrm{PbI}_{2}$ film at $100{ }^{\circ} \mathrm{C}$ for $5 \mathrm{~min}$, it showed a similar XRD pattern to that of the $\mathrm{PbI}_{2}$ film with DMF. The DMSO-retarded crystallization mechanism describes how DMSO has stronger coordination ability with $\mathrm{PbI}_{2}$ than $\mathrm{DMF}$, and the intermediate state of $\mathrm{PbI}_{2}(\mathrm{DMSO})_{\mathrm{x}}$ is generated in $\mathrm{PbI}_{2}$ solution with mixed solvent. On the other hand, DMSO has a higher boiling point $\left(189^{\circ} \mathrm{C}\right)$ than $\mathrm{DMF}\left(152.8^{\circ} \mathrm{C}\right)$, and a lower vapor pressure $\left(0.76 \mathrm{kPa}\right.$ at $\left.60^{\circ} \mathrm{C}\right)$ [19]. Based on these reasons, the spin-coating process of $\mathrm{PbI}_{2}$ in mixed solvent describes how the $\mathrm{PbI}_{2}$ solution is concentrated with DMF evaporation, and the $\mathrm{PbI}_{2}-\mathrm{DMSO}$ phase is formed simultaneously. DMSO helps to retard the rapid crystallization of $\mathrm{PbI}_{2}$ during the spin-coating process, resulting in a uniform $\mathrm{PbI}_{2}$ wet film.
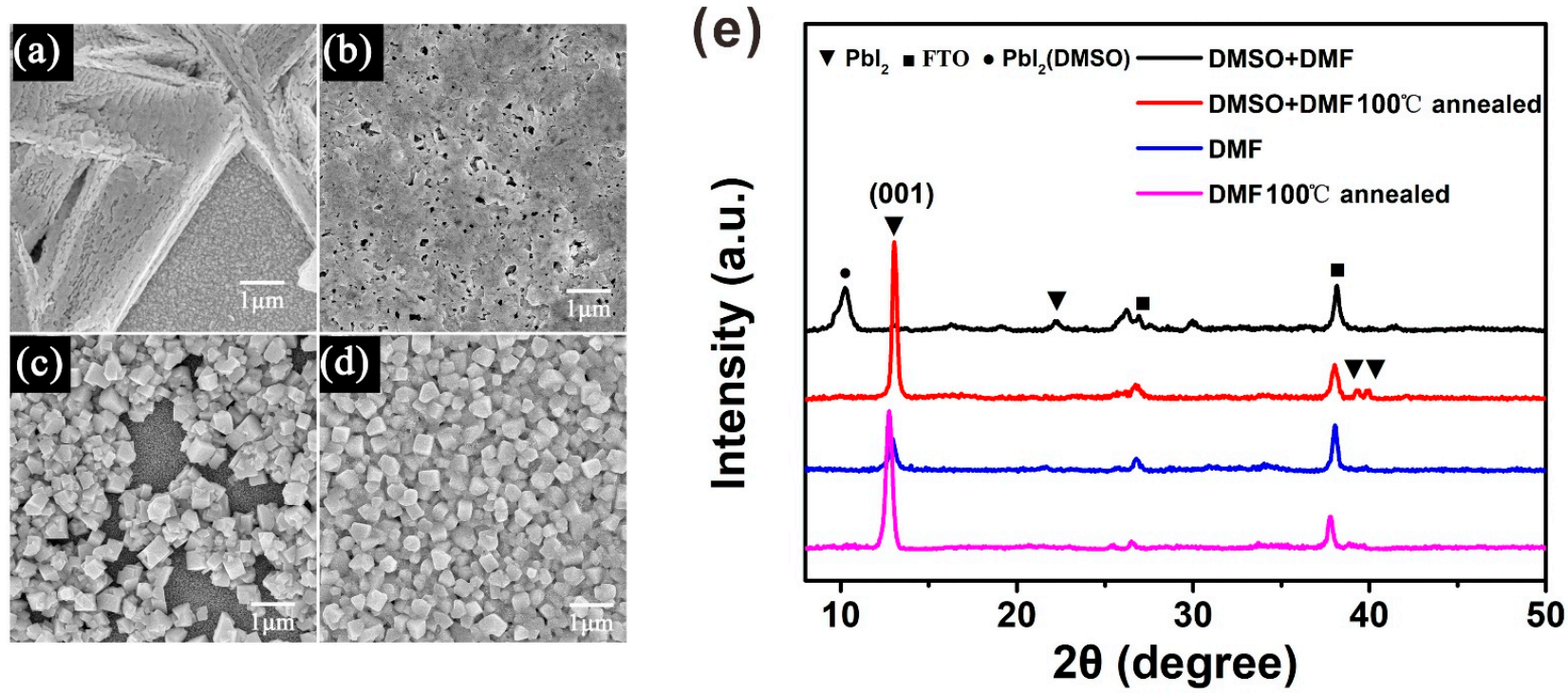

Figure 2. Characterization of $\mathrm{PbI}_{2}$ and $\mathrm{MAPbI}_{3}$ perovskite films without and with DMSO. (a) The top view image of SEM for $\mathrm{PbI}_{2}$ film without DMSO. (b) The top view image of SEM for $\mathrm{PbI}_{2}$ film with DMSO. (c) $\mathrm{MAPbI}_{3} \mathrm{SEM}$ top view image corresponding to $\mathrm{PbI}_{2}$ film without DMSO. (d) $\mathrm{MAPbI}_{3}$ SEM top view image corresponding to $\mathrm{PbI}_{2}$ film with DMSO. (e) XRD patterns of $\mathrm{PbI}_{2}$ films without and with DMSO.

In order to improve the morphology of the $\mathrm{PbI}_{2}$ film further, the $\mathrm{PbI}_{2}$ wet film was exposed to air for tens of seconds, and then the ethanol treatment was introduced. Compared with the $\mathrm{PbI}_{2}$ film without ethanol treatment (Figure 3a), we observe that the $\mathrm{PbI}_{2}$ film exhibits a porous morphology, with flake-like $\mathrm{PbI}_{2}$ crystals, as shown in Figure $3 b$. The $\mathrm{PbI}_{2}$ without ethanol treatment has enough time to nucleate and grow; hence, the $\mathrm{PbI}_{2}$ crystal nucleus can grow bigger and hold together. After ethanol treatment, the $\mathrm{PbI}_{2}$ film becomes rougher and more porous, thus creating a beneficial condition for $\mathrm{PbI}_{2}$ to react 
with $\mathrm{MAI}$ and form $\mathrm{MAPbI}_{3}$ film. The morphologies of $\mathrm{PbI}_{2}$ and $\mathrm{MAPbI}$ films depend on the exposure time of the $\mathrm{PbI}_{2}$ wet film, as displayed in Figure S2. The results confirm that the optimal exposure time is $30 \mathrm{~s}$. After heating the solvent-treated films at $100{ }^{\circ} \mathrm{C}$ for $5 \mathrm{~min}$, we note that the diffraction peak intensity at $12.6^{\circ}$ of $\mathrm{PbI}_{2}$ film based on the mixed solvent and ethanol treatment is much lower than those of the other $\mathrm{PbI}_{2}$ films, as presented in Figure 3c. It can be clearly indicated that the crystallization of the $\mathrm{PbI}_{2}$ film is lowered by ethanol treatment in combination with mixed solvent. It is known that ethanol can hardly dissolve $\mathrm{PbI}_{2}$, but it can separate out the solvent after treating the $\mathrm{PbI}_{2}$ film. Therefore, the period for the nucleation and crystal growth of $\mathrm{PbI}_{2}$ is restrained, resulting in the decline in $\mathrm{PbI}_{2}$ crystallinity. Figure 3c shows that the intensity of the (001) peak of the $\mathrm{PbI}_{2}$ film based on the mixed solvent and ethanol treatment is greatly inferior to that of the $\mathrm{PbI}_{2}$ film with $\mathrm{DMF}$ and ethanol treatment, which results from the higher boiling point of DMSO compared to DMF. Consequently, the nucleation and crystal growth of $\mathrm{PbI}_{2}$ in mixed solvent is suppressed. Furthermore, according to the XRD pattern of this reformative $\mathrm{PbI}_{2}$ film, the intensity of the (001) peak decreases and the (101) peak appears. This may suggest that the preferred crystallization orientation of $\mathrm{PbI}_{2}$ is changed by the ethanol treatment. The XRD spectra (Figure S3) of $\mathrm{PbI}_{2}$ with and without annealing have no difference, indicating that $\mathrm{PbI}_{2}$ film crystallization was accomplished after ethanol treatment. We attribute the transformation of $\mathrm{PbI}_{2}$ crystallization orientation to the changing $\mathrm{PbI}_{2}$ growth direction. By annealing the $\mathrm{PbI}_{2}$ film, the growth direction of $\mathrm{PbI}_{2}$ is altered from a substrate to $\mathrm{PbI}_{2}$ film. In contrast, as we introduce ethanol treatment, the growth direction is altered from a $\mathrm{PbI}_{2}$ film to a substrate. Therefore, the preferred orientation of the film is greatly influenced by the substrate composition and roughness [22]. Consequently, the $\mathrm{PbI}_{2}$ films generally exhibit (001) lattice plane preferred orientation if traditional annealing is introduced. As we introduce ethanol treatment, the $\mathrm{PbI}_{2}(001)$ lattice plane preferred orientation is suppressed, which is attributed to the influence of the released substrate on the $\mathrm{PbI}_{2}$ crystallization process.

Previous studies have shown that both reducing the preferred orientation and producing a porous morphology of $\mathrm{PbI}_{2}$ are beneficial to realize the full conversion of $\mathrm{PbI}_{2}$ to $\mathrm{MAPbI}_{3}$ [23]. Under the influence of these two aspects, the solvent-treated film sample (Figure 3d, red line) only showed a series of diffraction peaks of $\mathrm{MAPbI}_{3}$. For the sample without the solvent treatment (Figure $3 \mathrm{~d}$, black line), the diffraction peak $\left(12.6^{\circ}\right)$ of $\mathrm{PbI}_{2}$ still exists, indicative of an incomplete conversion of $\mathrm{PbI}_{2}$ to $\mathrm{MAPbI}_{3}$. Here, we emphasize that complete conversion is critical for the repeatability of the device. Because the amount of residual $\mathrm{PbI}_{2}$ is uncontrollable in an uncompleted conversion perovskite layer, the ratios of $\mathrm{MAPbI}_{3}$ to $\mathrm{PbI}_{2}$ are different between batches, which decreases the reproducibility of solar cells. Furthermore, photolysis of $\mathrm{MAPbI}_{3}$ introduces trap states and reduces the long-term stability of the device [24].

With the mixed solvent and ethanol treatment strategy, a thick $\mathrm{MAPbI}_{3}$ layer without residual $\mathrm{PbI}_{2}$ can be obtained. Moreover, the influence of the thickness of the perovskite capping layer on the performance of solar cells was investigated under different spin speeds of $\mathrm{PbI}_{2}$, from 6000 r.p.m. to 1000 r.p.m. The perovskite capping layer is the perovskite layer that covers the mesoporous $\mathrm{TiO}_{2}$. From the typical cross-sectional figures (Figure S4) of $\mathrm{PbI}_{2}$ films, we can observe that the thickness of the $\mathrm{PbI}_{2}$ capping layer increases as the rotating speed decreases from 6000 r.p.m. to 1000 r.p.m., and eventually reaches $300 \mathrm{~nm}$. The thickness of the perovskite capping layer follows the same trend as that shown in Figure S5, and can reach $550 \mathrm{~nm}$. It is obvious that the coverage ratio of $\mathrm{MAPbI}_{3}$ is also determined by the thickness of $\mathrm{PbI}_{2}$ (Figure 4). When the spin speed of $\mathrm{PbI}_{2}$ is less than or equal to 3000 r.p.m., a uniform and full coverage $\mathrm{MAPbI}_{3}$ on the mesoporous $\mathrm{TiO}_{2}$ substrate is obtained, further improving the morphology of the $\mathrm{MAPbI}_{3}$ perovskite layer. 
(a)

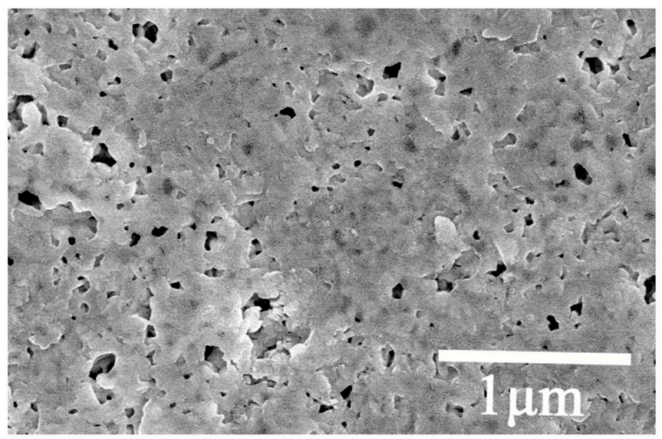

(c)

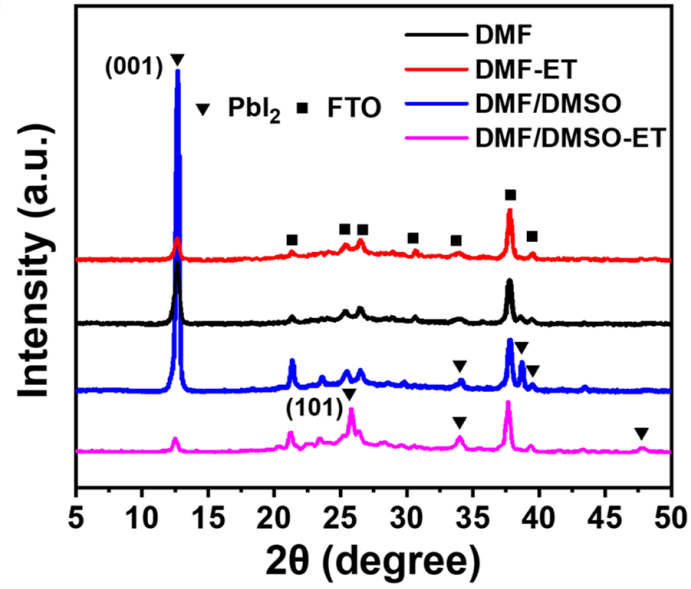

(b)

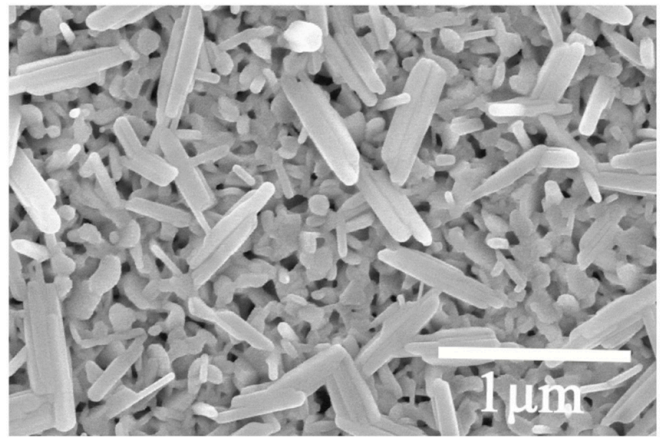

(d)

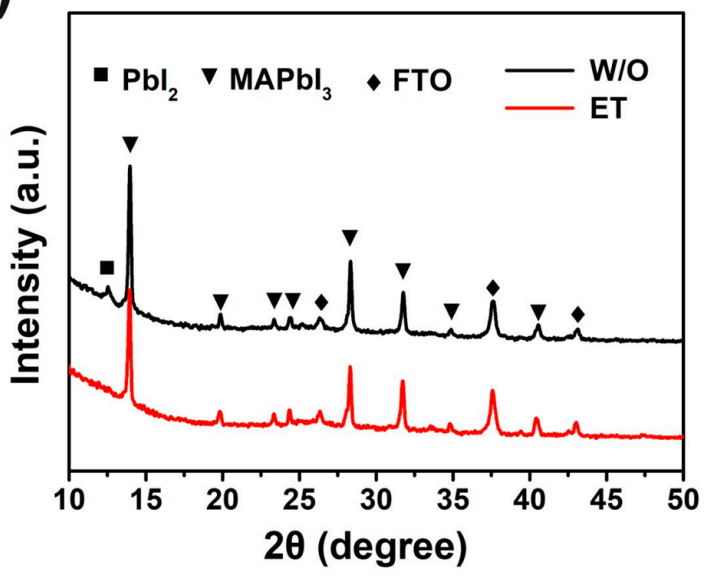

Figure 3. Characterization of $\mathrm{PbI}_{2}$ and $\mathrm{MAPbI}_{3}$ perovskite films without and with ethanol treatment. (a) SEM top view image of $\mathrm{PbI}_{2}$ film without ethanol treatment. (b) SEM top view image of $\mathrm{PbI}_{2}$ film with ethanol treatment. (c) XRD patterns of $\mathrm{PbI}_{2}$ films without and with ethanol treatment. (d) XRD patterns of corresponding $\mathrm{MAPbI}_{3}$ films without (black line) and with (red line) ethanol treatment.

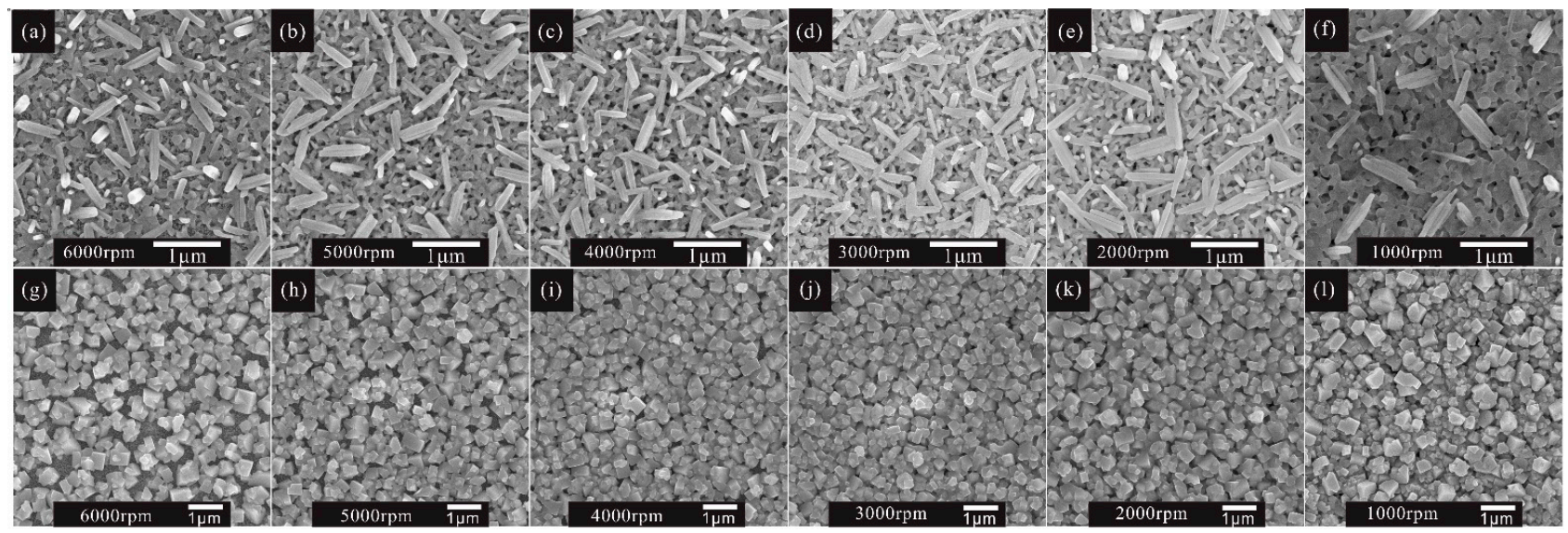

Figure 4. SEM top view images of $\mathrm{PbI}_{2}$ films prepared under different spin-coating speeds from (a-f) 6000 r.p.m. to 1000 r.p.m., and corresponding $\mathrm{MAPbI}_{3}$ films (g-1), respectively.

In order to investigate the influence of perovskite thickness on the performance of solar cells, we fabricated a series of devices with different rotating speeds of $\mathrm{PbI}_{2}$. Figure $5 \mathrm{a}$ demonstrates the $\mathrm{J}-\mathrm{V}$ characteristics of the perovskite solar cells under different rotating speeds; their corresponding statistical photovoltaic parameters are shown in Figure $5 c$ 
and listed in Table 1. The perovskite solar cell fabricated with a 6000 r.p.m. rotating speed of $\mathrm{PbI}_{2}$ shows a $\mathrm{V}_{\mathrm{OC}}$ of $844 \mathrm{mV}$, JSC of $16.2 \mathrm{~mA} \mathrm{~cm}^{-2}$, FF of $49.8 \%$, and PCE of $6.8 \%$. As the rotating speed of $\mathrm{PbI}_{2}$ decreases, all the parameters improve simultaneously. The enhanced PCE is owed to the enlarged $\mathrm{J}_{\mathrm{SC}}, \mathrm{V}_{\mathrm{OC}}$, and FF, as shown in Figure 5c. As mentioned previously, by using a low rotating speed in the $\mathrm{PbI}_{2}$ spin-coating process, the thick $\mathrm{MAPbI}_{3}$ capping layers have a better coverage rate than that when using a high rotating speed. It is obvious that the perovskite layer with a better coverage rate can absorb more light and suppress carrier recombination, which is certified by the larger JSC of the device with a lower spin speed of $\mathrm{PbI}_{2}$. According to the UV-vis absorption spectra, as shown in Figure 5b, more light can be absorbed by thicker perovskite films, resulting in a larger $\mathrm{J}_{\mathrm{SC}}$. As we know, the excellent coverage of the perovskite layer is beneficial to separate the carbon electrode from the $\mathrm{TiO}_{2}$ layer, thus resulting in a low recombination current and a high $\mathrm{V}_{\mathrm{OC}}$. Compared to the devices with $\mathrm{PbI}_{2}$ spin speeds of 3000 r.p.m. and 2000 r.p.m., we found that the coverage rate of the $\mathrm{MAPbI}_{3}$ film was almost similar to that displayed in Figure 4j,k. However, the PSCs with 2000 r.p.m. not only have a larger $\mathrm{J}_{\mathrm{SC}}$, but also have a higher $\mathrm{V}_{\mathrm{OC}}$ than those with 3000 r.p.m. The only difference is the thickness of the $\mathrm{MAPbI}_{3}$ capping layers. According to these results, we can conclude that increasing the thickness of the capping layer is beneficial to isolate the carbon electrode from the $\mathrm{TiO}_{2}$ layer; therefore, the charge recombination between the ETL and the carbon electrode is effectively suppressed. The series resistance $\left(R_{S}\right)$ and shunt resistance $\left(R_{S H}\right)$ were calculated using a single-diode model. The attained values of $R_{S}$ and $R_{S H}$ are listed in Table 1. The solar cells fabricated under a low rotating speed of $\mathrm{PbI}_{2}$ have larger $\mathrm{R}_{\mathrm{SH}}$ than those fabricated under a high rotating speed, which was consistent with the improved FF and $\mathrm{V}_{\mathrm{OC}}$ observed in these solar cells.

(a)
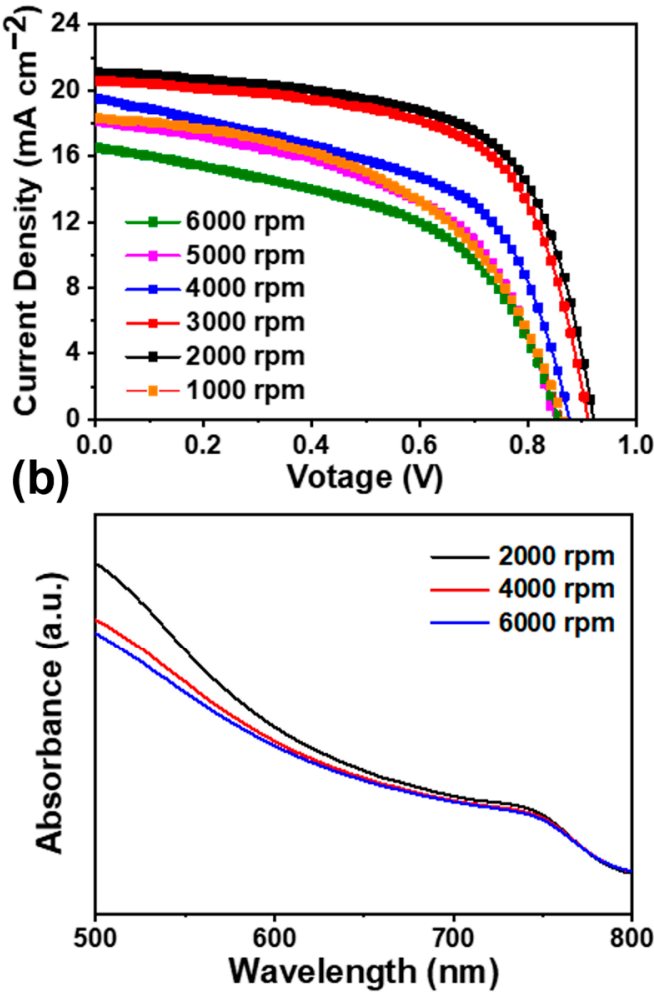

(c)

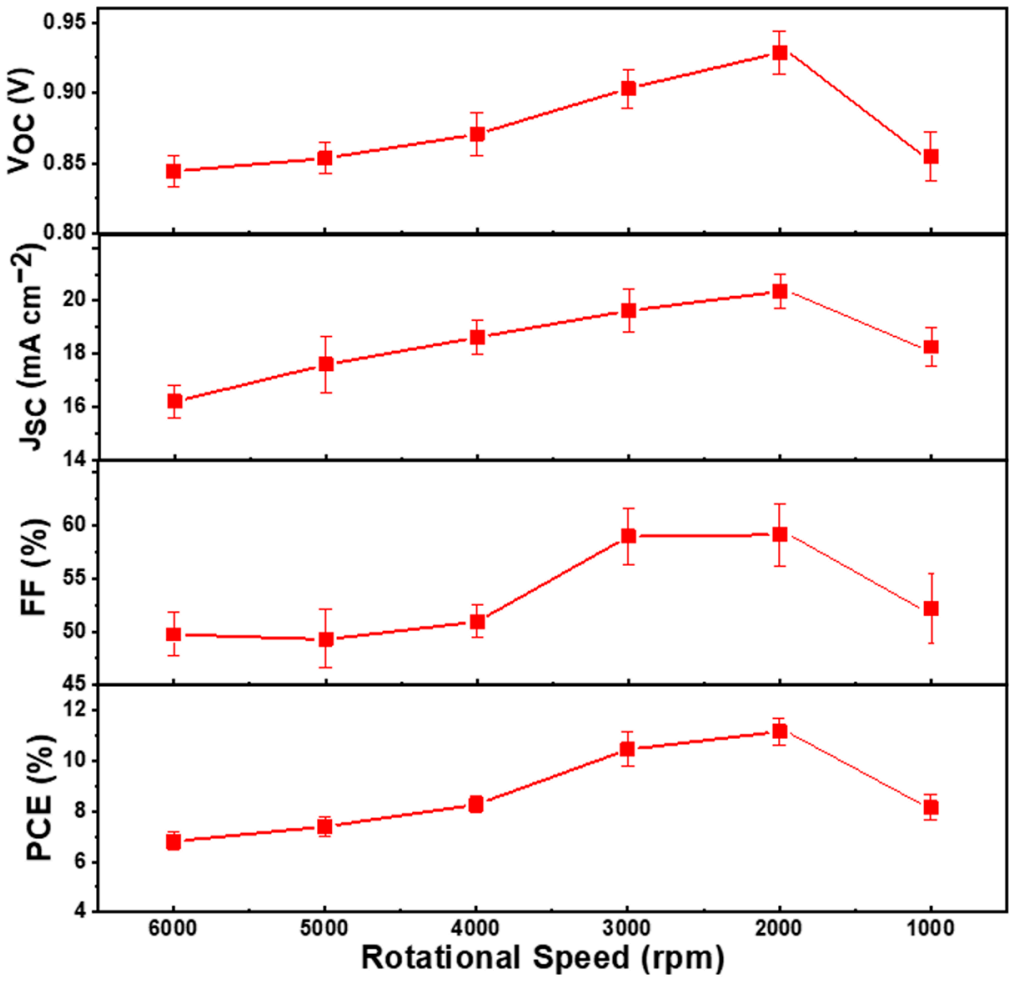

Figure 5. (a) J-V curves of perovskite solar cells prepared with $\mathrm{PbI}_{2}$ films under different spin-coating speeds from 6000 r.p.m. to 1000 r.p.m. (b) UV-vis absorption spectra of $\mathrm{MAPbI}_{3}$ films prepared under different spin-coating speeds of 6000, 4000, and 2000 r.p.m. for $\mathrm{PbI}_{2}$ films. (c) Variations in $\mathrm{V}_{\mathrm{OC}}, \mathrm{J}_{S C}$, FF and PCE under different spin-coating speeds from 6000 r.p.m. to 1000 r.p.m. 
Table 1. Statistics PV parameters of devices processed from $\mathrm{PbI}_{2}$ films with different spin-coating speeds.

\begin{tabular}{|c|c|c|c|c|c|c|}
\hline $\begin{array}{l}\text { Spin-Coating } \\
\text { Speed (r.p.m.) }\end{array}$ & $\begin{array}{l}\mathrm{V}_{\mathrm{OC}} \\
(\mathrm{mV})\end{array}$ & $\begin{array}{c}\text { JSC } \\
\left(\mathrm{mA} \mathrm{cm}^{-2}\right)\end{array}$ & $\begin{array}{l}\text { FF } \\
(\%)\end{array}$ & $\begin{array}{l}\text { PCE } \\
(\%)\end{array}$ & $\begin{array}{c}R_{S} \\
\left(\Omega \cdot \mathrm{cm}^{2}\right)\end{array}$ & $\begin{array}{c}\mathrm{R}_{\mathrm{SH}} \\
\left(\Omega \cdot \mathrm{cm}^{2}\right)\end{array}$ \\
\hline 1000 & $855 \pm 17$ & $18.3 \pm 0.7$ & $52.2 \pm 3.2$ & $8.2 \pm 0.5$ & 5.4 & 249.71 \\
\hline 2000 & $929 \pm 15$ & $20.4 \pm 0.7$ & $59.1 \pm 2.9$ & $11.2 \pm 0.5$ & 5.5 & 357.6 \\
\hline 3000 & $903 \pm 14$ & $19.6 \pm 0.8$ & $58.9 \pm 2.6$ & $10.5 \pm 0.7$ & 5.4 & 330.6 \\
\hline 4000 & $872 \pm 15$ & $18.6 \pm 0.7$ & $50.0 \pm 1.5$ & $8.3 \pm 0.3$ & 5.8 & 186.7 \\
\hline 5000 & $854 \pm 11$ & $17.6 \pm 1.0$ & $49.3 \pm 2.8$ & $7.4 \pm 0.4$ & 6.2 & 166.5 \\
\hline 6000 & $844 \pm 11$ & $16.2 \pm 0.6$ & $49.8 \pm 2.0$ & $6.8 \pm 0.4$ & 6.0 & 165.5 \\
\hline
\end{tabular}

The observed decrease in performance for the solar cells fabricated under 1000 r.p.m. is mainly due to the excessive thickness of the $\mathrm{MAPbI}_{3}$ layer, which could increase the leakage current of the device, which is further confirmed by the descended JSC and $\mathrm{V}_{\mathrm{OC}}$ of the devices. When 2000 r.p.m. was applied, a $~ 500 \mathrm{~nm}$ perovskite capping layer was attained. The device fabricated at this spinning speed showed excellent performance. The measured $\mathrm{V}_{\mathrm{OC}}, \mathrm{J}_{\mathrm{SC}}$, and $\mathrm{FF}$ are $929 \mathrm{mV}, 20.4 \mathrm{~mA} \mathrm{~cm}^{-2}$, and $59.1 \%$, respectively, which is equivalent to an average PCE of $11.9 \%$.

Due to the existence of hysteresis, the J-V measurement cannot evaluate the PCE of solar cells exactly. The differences in $\mathrm{V}_{\mathrm{OC}}$ and $\mathrm{J}_{\mathrm{SC}}$ are slight with forward scan and reverse scan. However, compared with the parameters under reverse scan, the FF obtained under forward scan is much lower (Figure 6). To precisely evaluate the performance of this device, a steady-state measurement was carried out for the device at the maximum power point (MPP). A J $\mathrm{SC}_{\mathrm{SC}}$ of $15.5 \mathrm{~mA} \mathrm{~cm} \mathrm{~cm}^{-2}$ was obtained when a bias voltage of $0.75 \mathrm{~V}$ was applied. Finally, the calculated PCE from the steady-state output measurement is $11.6 \%$.

(a)

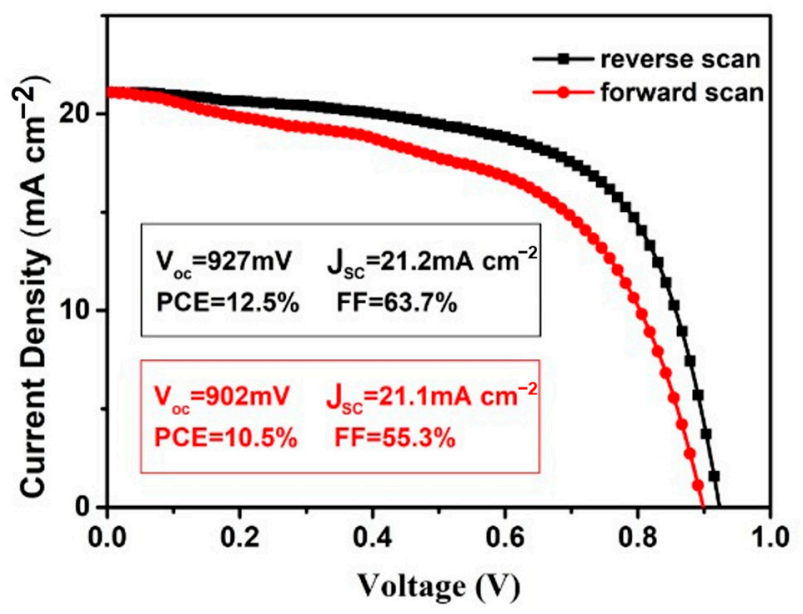

(b)

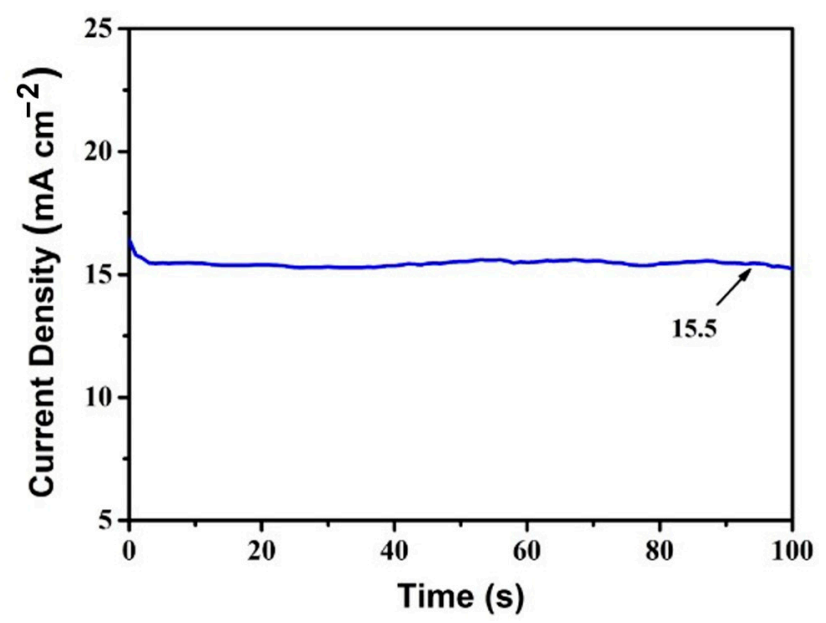

Figure 6. (a) J-V curves under reverse scan and forward scan with the preparation of $\mathrm{PbI}_{2}$ film under 2000 r.p.m. (b) Steady-state output measurements for this device.

\section{Materials and Methods}

\subsection{Materials}

All the materials were purchased from Sigma Aldrich unless otherwise stated. Methylammonium iodide (MAI), commercial carbon paste and FTO-coated glass substrates (Tec15) were purchased from Advanced Election Technology Co., Ltd. (Shenzhen, Guangdong, China)

\subsection{Preparation of $\mathrm{MAPbI}_{3}$ Film}

$\mathrm{PbI}_{2}$ (556 mg) was dissolved into $1 \mathrm{~mL}$ DMF or DMSO and DMF (volume ratio = 1:9) mixing solvent at $70{ }^{\circ} \mathrm{C}$ by stirring for $12 \mathrm{~h}$. Figure $1 \mathrm{c}$ demonstrates the primal deposition 
process of the $\mathrm{MAPbI}_{3}$ films. We dropped the $\mathrm{PbI}_{2}$ solution onto the mesoporous $\mathrm{TiO}_{2}{ }^{-}$ coated FTO substrate at 6000 r.p.m. for 30 s. The wet $\mathrm{PbI}_{2}$ films were annealed at $100{ }^{\circ} \mathrm{C}$ for $5 \mathrm{~min}$. Next, $7 \mathrm{mg} / \mathrm{mL}$ MAI isopropanol solution was loaded onto the substrate of $\mathrm{PbI}_{2}$ film for $120 \mathrm{~s}$, and then spun at 2000 r.p.m. for $30 \mathrm{~s}$ to remove excess solution. The modified sequential deposition process with mixture solvent and solvent treatment is shown in Figure $1 \mathrm{~d}$. Following this, $200 \mu \mathrm{L}$ ethanol was dripped onto the $\mathrm{PbI}_{2}$ wet film and dried using a $\mathrm{N}_{2}$ gun after $10 \mathrm{~s}$. The following process is the same as the primal sequential deposition process. The obtained $\mathrm{MAPbI}_{3}$ wet films were heated at $10{ }^{\circ} \mathrm{C}$ for $30 \mathrm{~min}$.

\subsection{Device Fabrication}

Solar cells were prepared under high-humidity ambient atmosphere. First, FTO-coated glass substrates were cleaned by ultrasonication in detergent, deionized water, acetone and isopropanol for $15 \mathrm{~min}$, respectively. Then, the substrates were dried with a $\mathrm{N}_{2}$ gun and subjected to an ultraviolet/ozone cleaning system for $15 \mathrm{~min}$. Subsequently, the titanium diisopropoxide bis(acetylacetonate) solution (75\% in 2-propanol, Sigma-Aldrich) diluted in isopropanol $(0.15 \mathrm{M})$ was spin-coated onto the FTO substrates at 4000 r.p.m. for $30 \mathrm{~s}$ and annealed at $150{ }^{\circ} \mathrm{C}$ for $10 \mathrm{~min}$.

A commercial $\mathrm{TiO}_{2}$ paste (Dyesol 18NRT, Greatcell) diluted in ethanol (1:2.5, weight ratio) was dropped onto the compact $\mathrm{TiO}_{2}$ and spun at 3000 r.p.m. for 30 s. After drying at $100{ }^{\circ} \mathrm{C}$, the $\mathrm{TiO}_{2}$ thin films were annealed at $500{ }^{\circ} \mathrm{C}$ for $30 \mathrm{~min}$ and then slowly cooled to room temperature. The mesoporous $\mathrm{TiO}_{2}$ was treated with a $\mathrm{TiCl}_{4}$ aqueous solution $(40 \mathrm{mM})$ at $70{ }^{\circ} \mathrm{C}$ for $30 \mathrm{~min}$. After that, the substrate was washed with ethanol and deionized water. The $\mathrm{CH}_{3} \mathrm{NH}_{3} \mathrm{PbI}_{3}$ film was fabricated using the sequential deposition method. Finally, a counter electrode was prepared by doctor blading the commercial carbon paste onto the perovskite film and annealed at $100{ }^{\circ} \mathrm{C}$ for $30 \mathrm{~min}$.

\subsection{Characterization}

The XRD spectra were produced by Bruker D8 Advance X-ray diffractometer (Bruker, Karlsruhe, Germany) with $\mathrm{Cu} \mathrm{K} \alpha$ as the radiation source. The top view and cross-sectional SEM images were collected on SU8010 (Hitachi, Tokyo, Japan) and the electron beam was accelerated at $5 \mathrm{kV}$. Ultraviolet-visible absorption spectra were obtained by PerkinElmer Lambda 35 (PerkinElmer, Waltham, Massachusetts, United States) in the range of 300 to $800 \mathrm{~nm}$ at room temperature. Photocurrent-voltage characteristics were obtained on a Keithley 2400 Source Meter under AM 1.5 illumination (Oriel Instruments, Franklin, MA, USA), which was calibrated by a Si reference cell. The J-V curves were measured by reverse $(1.0 \rightarrow-0.1 \mathrm{~V})$ or forward $(-0.1 \rightarrow 1.0 \mathrm{~V})$ scan, with a scan rate of $50 \mathrm{mV} \mathrm{s}^{-1}$. The measured area was confirmed with a metal mask of $0.09 \mathrm{~cm}^{-2}$.

\section{Conclusions}

In summary, a simple and effective modified sequential deposition method to fabricate high-quality perovskite film in high humidity was demonstrated. By applying the mixed solvent in combination with ethanol treatment, a thick, uniform and porous $\mathrm{PbI}_{2}$ film is formed in the first step. The porous morphology and reduced crystallization orientation of the $\mathrm{PbI}_{2}$ film facilitates the diffusion of the MAI solution, and, thus, the $\mathrm{PbI}_{2}$ film with a thickness of $800 \mathrm{~nm}$ can be completely converted to $\mathrm{MAPbI}_{3}$ perovskite in only two minutes. By improving the thickness of the perovskite capping layer, the coverage rate of perovskite is increased further. Obviously, the compact and thick perovskite films strengthen the absorption of incident light, and act as an insulating layer to suppress the carrier recombination between the ETL and carbon counter electrode. Therefore, enhanced photovoltaic parameters are observed. With the optimized thickness of the perovskite layer, the HTM-free carbon-based perovskite solar cell exhibits a superior PCE of $12.5 \%$. In addition, this work provides an excellent approach to fabricating the $\mathrm{MAPbI}_{3}$ perovskite layer in air for solar cells and other photoelectric devices. 
Supplementary Materials: The following are available online, Figure S1: Photograph of PbI2 films with (left) and without DMSO (right). Figure S2: SEM top view images of PbI2 films prepared under different exposure time from (b-f) $10 \mathrm{~s}$ to $30 \mathrm{~s}$, and corresponding MAPbI3 films (f-h), respectively. Figure S3: XRD patterns of corresponding MAPbI3 films without (black line) and with annealing (red line). Figure S4: Cross-sectional SEM images of PbI2 films prepared under different spin-coating speeds from (a-f) 6000 r.p.m. to 1000 r.p.m. Figure S5: Cross-sectional SEM images of MAPbI3 films corresponding PbI2 films prepared under different spin-coating speeds from (a-f) 6000 r.p.m. to 1000 r.p.m.

Author Contributions: Conceptualization, S.H. and G.H.; methodology, D.C. and J.W.; validation, H.S. and L.L.; formal analysis, L.Z. and Q.K.; investigation, L.Z. and D.C.; data curation, J.W. and H.S.; writing-original draft preparation, L.Z. and D.C.; writing-review and editing, J.W., S.H. and G.H. All authors have read and agreed to the published version of the manuscript.

Funding: Shihua Huang would like to acknowledge funding from the Key Research and Development Program of Zhejiang Province (2021C01006), the National Key R\&D Program of China (2018YFB1500102). Dan Chi would like to acknowledge funding from the Education Department of Zhejiang Province (Y202147258) and the Zhejiang Provincial Natural Science Foundation of China (No. LQ18F040002).

Institutional Review Board Statement: Not applicable.

Informed Consent Statement: Not applicable.

Data Availability Statement: Data will be available from the corresponding author upon logical request.

Acknowledgments: This work was supported by the Education Department of Zhejiang Province (Y202147258), the Key Research and Development Program of Zhejiang Province (2021C01006), the National Key R\&D Program of China (2018YFB1500102), Zhejiang Provincial Natural Science Foundation of China (No. LY17F040001, LQ18F040002), Zhejiang Provincial Key Laboratory (No. 2013E10022).

Conflicts of Interest: The authors declare no conflict of interest.

Sample Availability: Not available.

\section{References}

1. Yang, W.S.; Noh, J.H.; Jeon, N.J.; Kim, Y.C.; Ryu, S.; Seo, J.; Seok, S.I. High-performance photovoltaic perovskite layers fabricated through intramolecular exchange. Science 2015, 348, 1234-1237. [CrossRef] [PubMed]

2. Saki, Z.; Byranvand, M.M.; Taghavinia, N.; Kedia, M.; Saliba, M. Solution-processed perovskite thin-films: The journey from labto large-scale solar cells. Energy Environ. Sci. 2021, 14, 5690-5722. [CrossRef]

3. Zhang, X.; Ma, S.; You, J.; Bai, Y.; Chen, Q. Tailoring Molecular Termination for Thermally Stable Perovskite Solar Cells. J. Semicond. 2021, 42, 112201. [CrossRef]

4. Xu, J.; Maxwell, A.; Wei, M.; Wang, Z.; Chen, B.; Zhu, T.; Sargent, E.H. Defect Tolerance of Mixed B-Site Organic-Inorganic Halide Perovskites. ACS Energy Lett. 2021, 6, 4220-4227. [CrossRef]

5. $\quad$ Li, X.; Meng, Y.; Liu, R.; Yang, Z.; Zeng, Y.; Yi, Y.; Sha, W.E.I.; Long, Y.; Yang, J. High-Efficiency and Durable Inverted Perovskite Solar Cells with Thermally-Induced Phase-Change Electron Extraction Layer. Adv. Energy Mater. 2021, 11, 2102844. [CrossRef]

6. Jiang, Q.; Zhao, Y.; Zhang, X.; Yang, X.; Chen, Y.; Chu, Z.; Ye, Q.; Li, X.; Yin, Z.; You, J. Surface passivation of perovskite film for efficient solar cells. Nat. Photonics 2019, 13, 460-466. [CrossRef]

7. Lamberti, F.; Schmitz, F.; Chen, W.; He, Z.; Gatti, T. The Non-Innocent Role of Hole-Transporting Materials in Perovskite Solar Cells. Sol. RRL 2021, 5, 2100514. [CrossRef]

8. Zhang, L.; Zuo, C.; Ding, L. Efficient MAPbI3solar Cells Made via Drop-Coating at Room Temperature. J. Semicond. 2021, $42,072201$. [CrossRef]

9. Wang, R.; Mujahid, M.; Duan, Y.; Wang, Z.K.; Xue, J.; Yang, Y. A Review of Perovskites Solar Cell Stability. Adv. Funct. Mater. 2019, 29, 1808843. [CrossRef]

10. Li, Z.; Yang, G. A Methylammonium Iodide Healing Method for CH3NH3PbI3 Perovskite Solar Cells with High Fill Factor over 80\%. J. Semicond. 2021, 42, 112202. [CrossRef]

11. Arora, N.; Dar, M.I.; Hinderhofer, A.; Pellet, N.; Schreiber, F.; Zakeeruddin, S.M.; Grätzel, M. Perovskite solar cells with CuSCN hole extraction layers yield stabilized efficiencies greater than 20\%. Science 2017, 358, 768-771. [CrossRef] [PubMed]

12. Ku, Z.; Rong, Y.; Xu, M.; Liu, T.; Han, H. Full printable processed mesoscopic $\mathrm{CH}_{3} \mathrm{NH}_{3} \mathrm{PbI}_{3} / \mathrm{TiO}_{2}$ heterojunction solar cells with carbon counter electrode. Sci. Rep. 2013, 3, 3132. [CrossRef] [PubMed] 
13. Chen, H.N.; Wei, Z.H.; He, H.X.; Zheng, X.L.; Wong, K.S.; Yang, S.H. Solvent Engineering Boosts the Efficiency of Paintable Carbon-Based Perovskite Solar Cells to beyond 14\%. Adv. Energy Mater. 2016, 6, 1502087. [CrossRef]

14. Pang, S.; Hu, H.; Zhang, J.; Lv, S.; Yu, Y.; Wei, F.; Qin, T.; Xu, H.; Liu, Z.; Cui, G. $\mathrm{NH}_{2} \mathrm{CH}=\mathrm{NH}_{2} \mathrm{PbI}_{3}$ : An alternative organolead iodide perovskite sensitizer for mesoscopic solar cells. Chem. Mater. 2014, 26, 1485-1491. [CrossRef]

15. Xu, Y.; Zhu, L.; Shi, J.; Xu, X.; Xiao, J.; Dong, J.; Wu, H.; Luo, Y.; Li, D.; Meng, Q. The Effect of Humidity upon the Crystallization Process of Two-Step Spin-Coated Organic-Inorganic Perovskites. ChemPhysChem 2016, 17, 112-118. [CrossRef]

16. Ball, J.M.; Petrozza, A. Defects in perovskite-halides and their effects in solar cells. Nat. Energy 2016, 1, 16149. [CrossRef]

17. Cheng, N.; Liu, P.; Bai, S.; Yu, Z.; Liu, W.; Guo, S.S.; Zhao, X.Z. Application of mesoporous SiO2 layer as an insulating layer in high performance hole transport material free CH3NH3PbI3 perovskite solar cells. J. Power Sources 2016, 321, 71-75. [CrossRef]

18. Hu, Y.; Si, S.; Mei, A.; Rong, Y.; Liu, H.; Li, X.; Han, H. Stable Large-Area $\left(10 \times 10 \mathrm{~cm}^{2}\right)$ Printable Mesoscopic Perovskite Module Exceeding 10\% Efficiency. Sol. RRL 2017, 1, 1600019. [CrossRef]

19. Wu, Y.; Islam, A.; Yang, X.; Qin, C.; Liu, J.; Zhang, K.; Peng, W.; Han, L. Retarding the crystallization of PbI2 for highly reproducible planar-structured perovskite solar cells via sequential deposition. Energy Environ. Sci. 2014, 7, 2934-2938. [CrossRef]

20. Jiang, Q.; Chu, Z.; Wang, P.; Yang, X.; Liu, H.; Wang, Y.; Yin, Z.; Wu, J.; Zhang, X.; You, J. Planar-Structure Perovskite Solar Cells with Efficiency beyond 21\%. Adv. Mater. 2017, 29, 1703852. [CrossRef] [PubMed]

21. Cheng, Y.; Xu, X.; Xie, Y.; Li, H.-W.; Qing, J.; Ma, C.; Lee, C.-S.; So, F.; Tsang, S.-W. 18\% High-Efficiency Air-Processed Perovskite Solar Cells Made in a Humid Atmosphere of 70\% RH. Sol. RRL 2017, 1, 1770131. [CrossRef]

22. Ohring, M. Chapter 1-A review of materials science. In Materials Science of Thin Films, 2nd ed.; Academic Press: San Diego, CA, USA, 2002; pp. 1-56.

23. Miyadera, T.; Shibata, Y.; Koganezawa, T.; Murakami, T.N.; Sugita, T.; Tanigaki, N.; Chikamatsu, M. Crystallization Dynamics of Organolead Halide Perovskite by Real-Time X-ray Diffraction. Nano Lett. 2015, 15, 5630-5634. [CrossRef] [PubMed]

24. Roose, B.; Dey, K.; Chiang, Y.; Friend, R.H.; Stranks, S.D. Critical Assessment of the Use of Excess Lead Iodide in Lead Halide Perovskite Solar Cells. J. Phys. Chem. Lett. 2020, 11, 6505-6512. [CrossRef] [PubMed] 